\title{
Design of Brake Control System on Sounding Rocket Experiment
}

\author{
By Toru SUZUKI ${ }^{1)}$, Tomoya MAZAWA ${ }^{1)}$, Takeo WATANABE ${ }^{1)}$, Hironori A FUJII ${ }^{2)}$ \\ ${ }^{1)}$ Department of system design, Tokyo Metropolitan University, Japan \\ ${ }^{2)}$ Nihon University, Tokyo, Japan
}

(Received April 30th, 2008)

\begin{abstract}
One engineering experiment and two scientific experiments are scheduled by using the bare electro-dynamic tape tether on the S520 sounding rocket in 2009. Purpose of the engineering experiment is a quick deployment of tape tether stored in the box with the foldaway storage method, which is a new concept of tether deployment schemes. The design of braking control system for foldaway tape tether deployer is studied in this paper. Braking drag force is measured by experiment in vacuum condition and air, and braking drag characteristic is analyzed from these results of several kinds of experiments.
\end{abstract}

Key Words: Brake Control System, Friction, Vacuum, Tape Tether

\section{Nomenclature}

$\begin{array}{ll}V & : \text { deployment velocity } \\ \mathrm{D} & \text { :deployment drag force } \\ \mathrm{F} & \text { :braking drag force } \\ \mathrm{W} & \text { :brake pads load } \\ \mu & \text { :coefficient of friction } \\ \mathrm{m} & \text { :number of contact side }\end{array}$

\section{Introduction}

The S520-25 sounding rocket of JAXA is scheduled to be launched in 2009 summer. Sounding rocket project is currently being carried out under an international cooperation in Japan, the United States, Europe and Australia ${ }^{1), 2)}$. In the sounding rocket experiment, engineering experiment and scientific experiment are proceeded by using the bare electro dynamic tape tether. Tape tether consists of Aluminum and PET film like Fig.1. In the engineering experiment, tape tether fast deployment up to $300 \mathrm{~m}$ in 120 seconds is performed. In the scientific experiment, gathering electron and verification of OML (Orbital-Motion-Limit) is performed by using tape tether.

For the engineering experiment of tape tether fast deployment, foldaway storage method as shown in Fig.2 is invented and adopted ${ }^{3)}$. In comparison with the conventional reel type as shown in Fig. 3, the foldaway storage method does not have problems such as back rush, and fast deployment is safely possible by this method with high confidence.

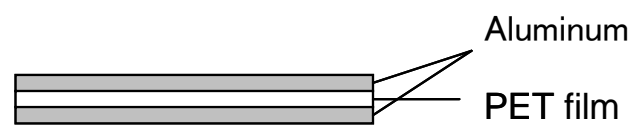

Fig. 1. Tape Tether

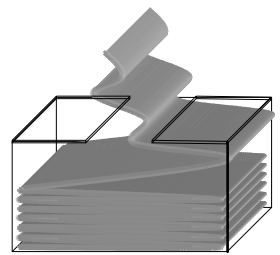

Fig. 2 Foldaway type deployment system

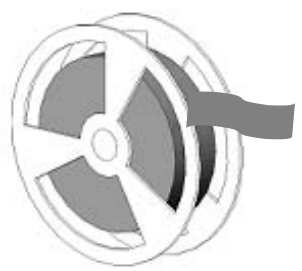

Fig. 3 Reel type deployment system

In the sounding rocket experiment, it is important that tape tether is certainly extended $300 \mathrm{~m}$ before the scientific experiment. In the case deployment speed remains when deployment finishes, daughter payload may bounce and tape tether may slack. Therefore, it is necessary to decelerate the deployment speed gradually by a brake control system and to bring it close to zero. Also because the engineering experiment is carried out at an altitude of $300 \mathrm{~km}$, deployment of tape tether takes place in the vacuum condition. In general, friction phenomenon in the vacuum condition is different from that in the atmosphere. The purpose of this study is to design a brake control system for the foldaway storage method and experimentally analyze the performance of the brake control system.

The tape tether deployment is carried out by ejecting a daughter payload connected with tape tether from the sounding rocket, as shown in Fig.4. The daughter payload is separated and ejected from the sounding rocket by the loaded springs force. Figure 5 shows an example of the time history of deployment velocity. The phase 3 corresponds to the braking duration. 


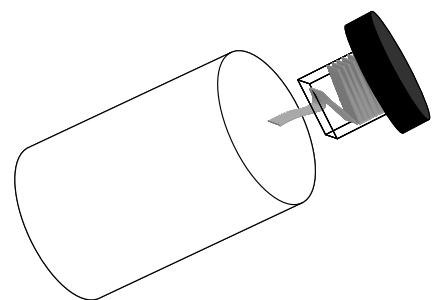

Fig. 4 Ejection of daughter payload

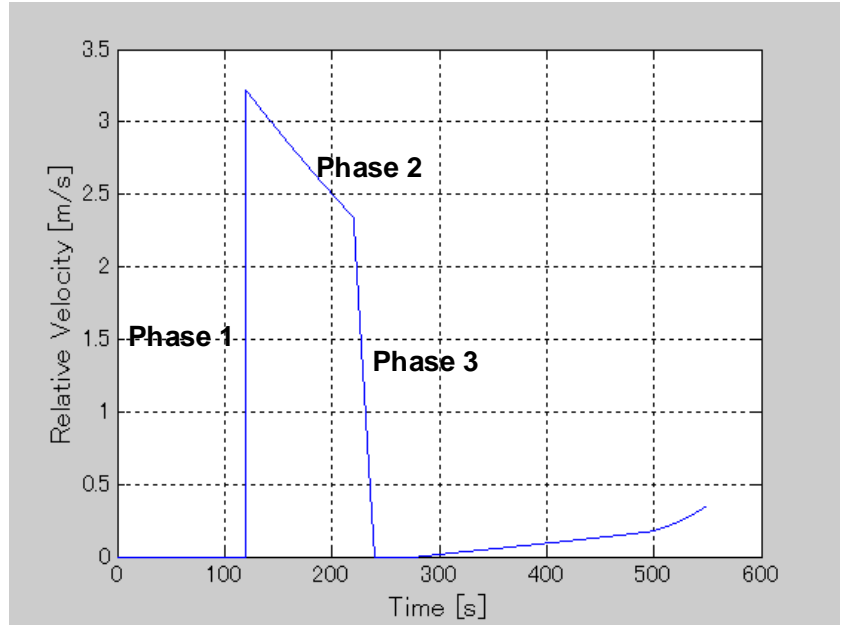

Fig. 5 Time history of deployment velocity

\section{Design of Brake Control System}

\subsection{Mechanism of brake control system}

In order to design the brake control system for the tape tether deployer, a concept of the brake was selected from several types of method, as shown in Fig.6: (a) the brake pad type method, (b) is the roller type and (c) the adhesive type. As a result of consideration, the brake pad type method is employed, because this method satisfies capability for the sounding rocket experiment.

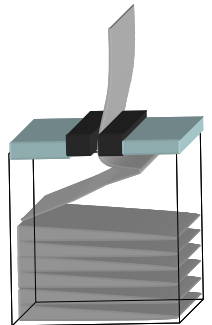

(a)

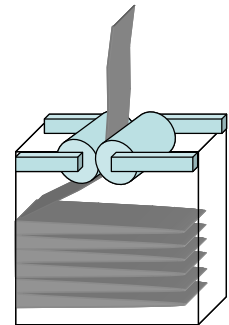

(b)

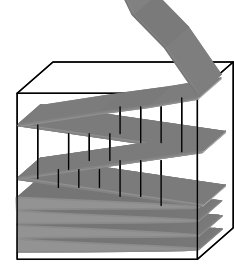

(c)
Fig.6 Method of brake control

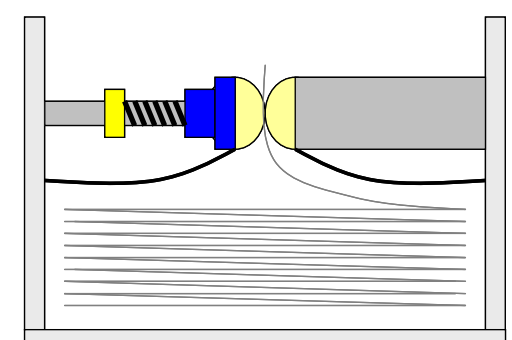

Fig.7 Schematic representation of the brake control system.

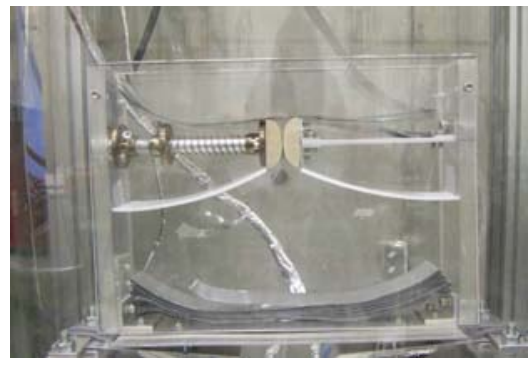

Fig. 8 Photograph of the brake control system.

Mechanism of pad type brake system is that one brake pad is held and the other brake pad is attached to a bush through the shaft to be able to move as shown in Figs.7, and 8. Brake pads are given load by a spring through the shaft. The spring is compressed and held by a shaft holder. In order to smoothly deploy tape tether, shape of the brake pads is round and a guide is placed.

\subsection{Deployment speed control}

Required braking drag force and length of tape tether are predicted by numerical simulations. Feedback control methods are not desired for controlling the deployment speed, because they require sensors and are not as reliable as expected. In order to control deployment speed successfully without feedback control, the tape tether storage box is designed as two stages composition as shown in Fig.9. The first stage is a part of tape tether deployment and the second stage is a brake part. This brake control system is expected to be very simple and to have high reliability because this system does not have any rotating mechanical elements.

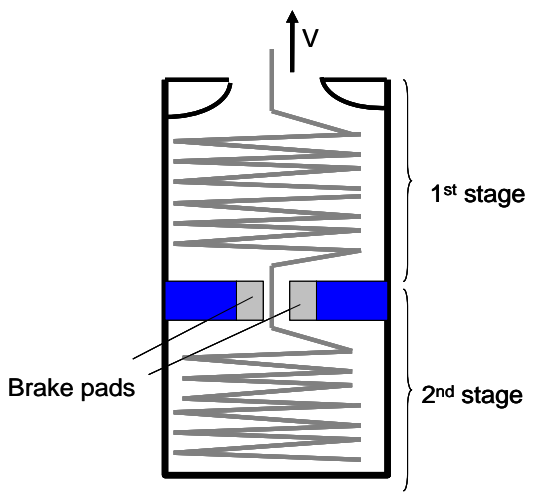

Fig. 9 Two stage tether box.

\subsection{Material of brake pads}

Super Sumika S300 produced by Yasojima Proceed is employed as material of brake pads. This material that is 
made by filling all aromatic polyester Sumika Super E101 to PTFE is an excellent resin in sliding. Advantages of the material are that friction drag is steady by the sliding characteristic of this material, and possibility of damage to tape tether is very low.

\subsection{Examination of friction heat}

The effect of frictional heat that occurred at the brake is examined according to the limit PV value. The PV value is often used as an index of the rise in heat in the friction side given by the product of average contact side pressure $\mathrm{P}$ and sliding speed $\mathrm{V}^{4), 5)}$. The limit PV value is PV value to keep the surface of sliding condition. In general, material is used under the sliding condition that $\mathrm{PV}$ value is less than $50 \%$ of the limit PV value ${ }^{6}$. Limit PV value of Smika Super S300 used as a brake pad material is about $7(\mathrm{MPa} \cdot \mathrm{m} / \mathrm{s})$. If the demanded braking drag is $5 \mathrm{~N}$, then the pad load becomes $5(\mathrm{~N})$, and the PV value at contact area $50\left(\mathrm{~mm}^{2}\right)$ and development speed $4(\mathrm{~m} / \mathrm{s})$ is $\frac{5[\mathrm{~N}]}{50 \times 10^{-6}\left[\mathrm{~m}^{2}\right]} \times 4[\mathrm{~m} / \mathrm{s}]=0.4[\mathrm{MPa} \cdot \mathrm{m} / \mathrm{s}]$

Because this value is about $6 \%$ of the limit $\mathrm{PV}$ value, it can be said that the effect of friction heat is very small.

\subsection{Theoretical equation of braking drag force}

According to Newton Amonton friction law, friction force is proportion to normal force exerted between the surface and independent on sliding speed. The theoretical equation of braking drag force is given by

$$
F=m \mu W+D
$$

\section{Measurement of Braking Drag Force}

\subsection{Experiment devise}

Tape tether deployment is operated by using a tower type deployment simulator, which consists of a pair of pinch rollers driven by a servomotor, the storage box, and an acrylic vacuum chamber. Figure 10 shows a schematic representation of the simulator and Fig. 11 shows a photograph of the simulator. In order to measure the braking drag force in vacuum condition, the simulator system is set in the acrylic vacuum chamber, and the braking drag is measured by load cells connected with an amplifier and recorded by a PC.

\subsection{Method of experiment}

102510 ALPET tape is employed as the tape tether that is to be used for the sounding rocket experiment. The tape tether storage box is installed on the load cells and tape tether is stored in the box. The deployment tests are operated with the reference speeds $(0.5 \mathrm{~m} / \mathrm{s}, 1.0 \mathrm{~m} / \mathrm{s}$, and $2.0 \mathrm{~m} / \mathrm{s})$ and the loads of the brake pad are set at $0.5 \mathrm{~N}, 0.5 \mathrm{~N}, 1 \mathrm{~N}$, and $1.5 \mathrm{~N}$ respectively. The strain data is stored in the $\mathrm{PC}$ at sampling rate of $1000 \mathrm{~Hz}$, and braking drag is estimated using difference between the weight resulting from the load cells and the calculated weight based on the length of tether remained in the box. In the case of experiment in vacuum condition, the vacuum chamber is evacuated by a vacuum pump. The degree of vacuum is approximately 15 Torr.

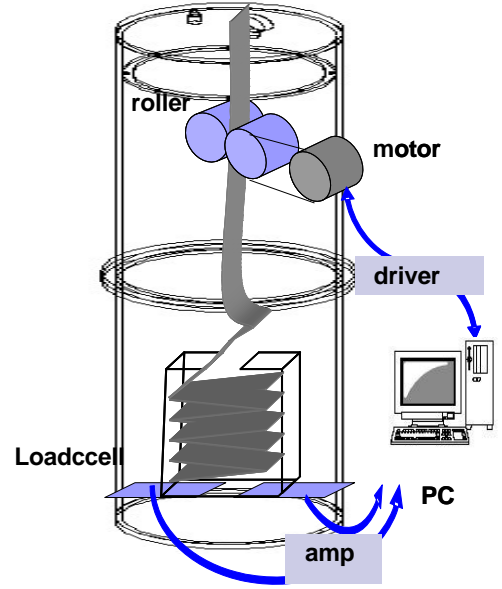

Fig. 10 Schematic representation of the experiment setup.

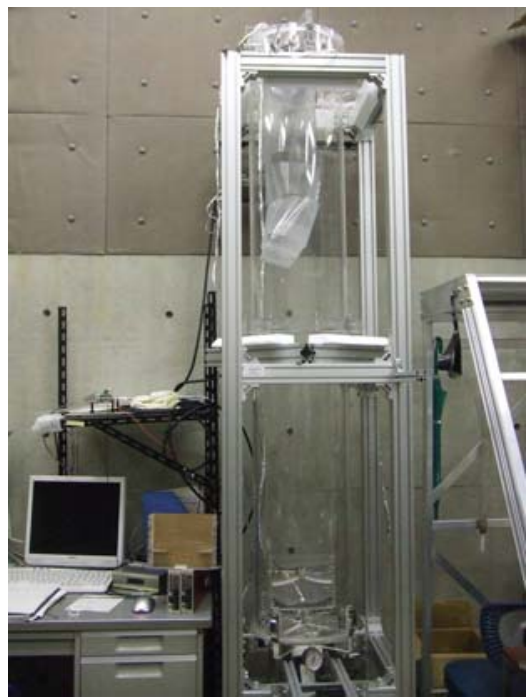

Fig.11 Photograph of the experimental setup.

\subsection{Results}

The braking drag at $0.5 \mathrm{~m} / \mathrm{s}, 1 \mathrm{~m} / \mathrm{s}$, and $2 \mathrm{~m} / \mathrm{s}$ deployment speed is shown in Figs.12, 13, and 14, respectively. The horizontal axis indicates the load given for the brake pads, and the vertical axis shows the braking drag force. The measured data can be expressed as line by a least squares method. Results in the atmosphere are shown with red, and results in the vacuum condition are shown with blue.

Figures 15 and 16 show a relationship between the braking drag and deployment speed in vacuum and in air, respectively. The horizontal axis is the deployment speed, and the vertical axis is breaking drag. It is shown in these figures that braking drag does not depend on the deployment speed, but on the pad load.

\section{Conclusion}

Brake control system is designed and studied experimentally for the foldaway tape tether deployer. From the experimental results, it is shown that braking drag in vacuum condition is greater than that in the air and that braking drag is proportion to pad load. Dependence of braking force on deployment speed is not observed at the range of deployment speed from $0.5 \mathrm{~m} / \mathrm{s}$ to $2 \mathrm{~m} / \mathrm{s}$. 


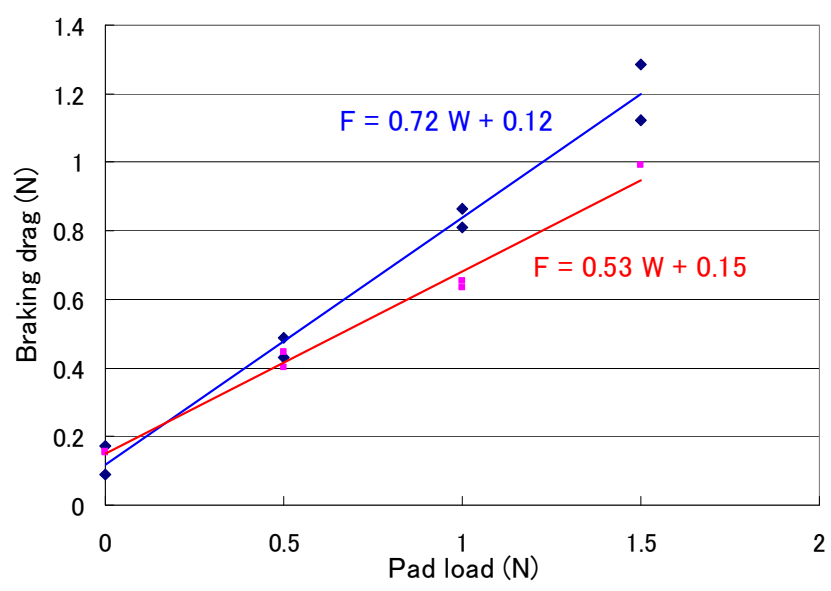

Fig. 12 Braking drag $(0.5 \mathrm{~m} / \mathrm{s})$.

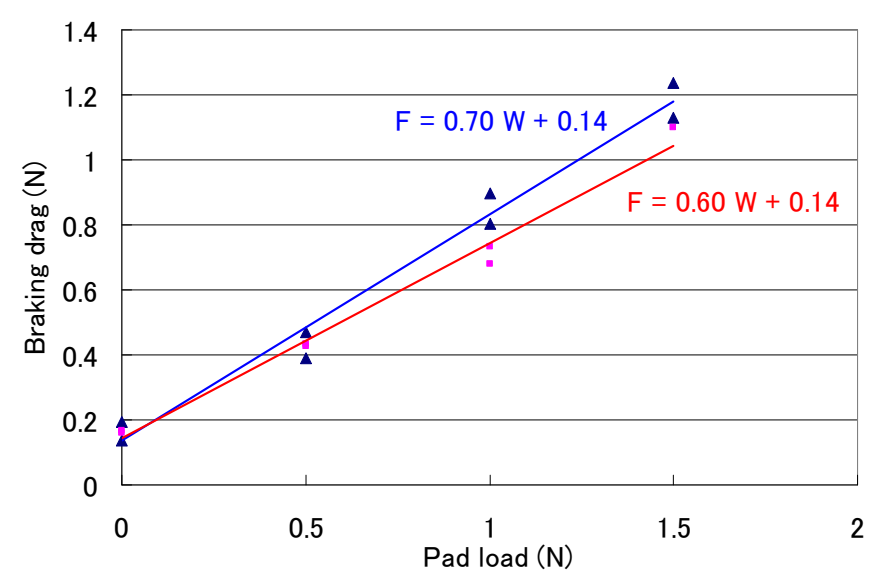

Fig. 13 Braking drag $(1 \mathrm{~m} / \mathrm{s})$.

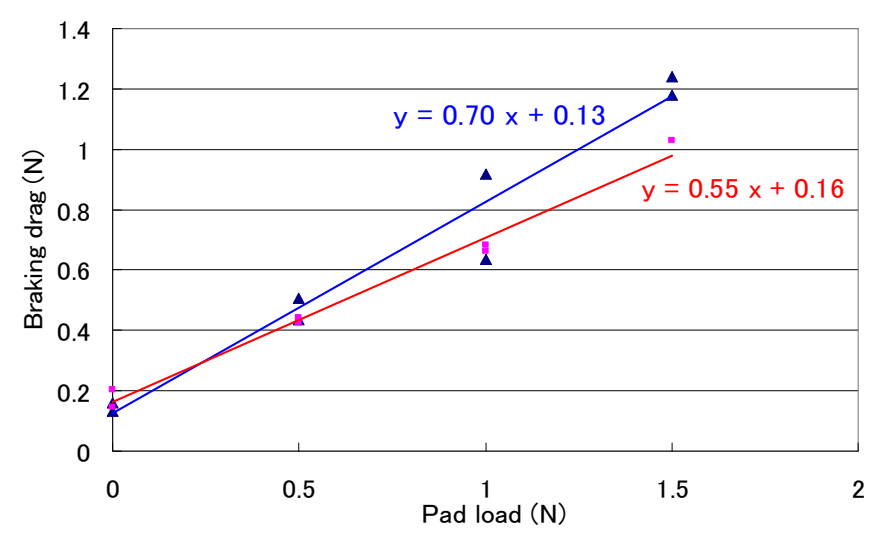

Fig. 14 Braking drag $(2 \mathrm{~m} / \mathrm{s})$.

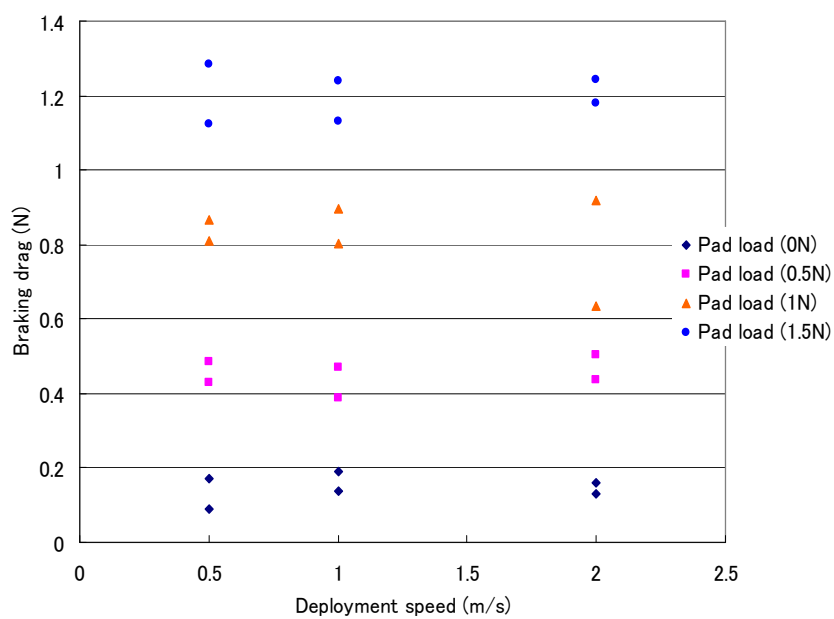

Fig. 15 Braking drag in vacuum.

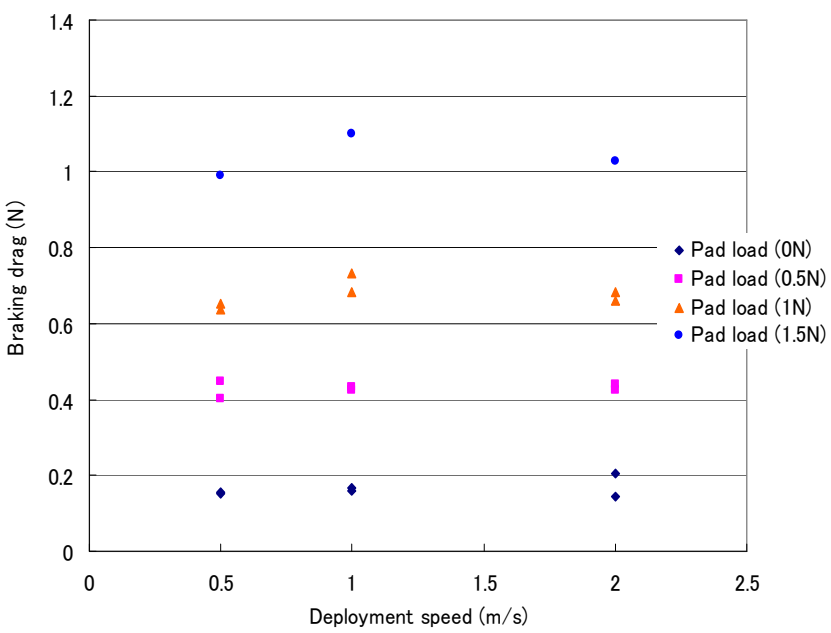

Fig. 16 Braking drag in air.

\section{Reference}

1) Fujii, A. H., Takegahara, H., Oyama, K., Sasaki, S., Yamagiwa, M., Krujff, M., Van der Heide, E. J., Sanmatrin, J. R., and Charro, M. "A proposed bare-tether experiment on board a sounding rocket," AIAA Guidance, Navigation, and Control Conference and Exhibit, at the Providence, RI, August 16-19 2004.

2) Fujii, A. H., Takegahara, H., et al., "A proposed Bare-Tether Experiment on board a Sounding Rocket, " $9^{\text {th }}$ Spacecraft Charging Technology Conference, 4-8 April 2005, JAXA Tsukuba, Japan.

3) Fujii, A H., Watanabe, T., Nakafushi, S., Kikuchi T., and Kusagaya, T., "Measurement of the Deployment Drag for Designing of the Foldaway Tape Tether Deployer," ISTS 2006-m-12.

4) Yamamoto, Y., and Kaneda, S., "Tribology," Rikougakusha Publishing Co. Ltd., Tokyo, 2007.

5) Kenneth C. Ludema. "Friction, wear, lubrication : a textbook in tribology," CRC Press, 1996.

6) http://www.sumitomo-chem.co.jp024SUMIPOYS_PROY_22syo udout.html 